\title{
SITUAÇÄO EPIDEMIOLÓGICA DA HANSENÍASE E DOS SEUS COMUNICANTES EM CAMPINAS
}

\author{
Maria Angélica Puntel Carrasco** \\ Elisete Silva Pedrazzani****
}

CARRASCO, M. A. P.; PEDRAZZANI, E. S. Situaçāo epidemiológica da Hanseniase e dos seus comunicantes em Campinas. Rev. Esc. Enf. USP, v. 27, n. 2, p. 214-218, ago. 1993.

A Hanseniase é uma doença endêmica e de alta prevalência entre a população do pais. Das endemias brasileiras, essa é a de mass longa duraçāo, trazendo como conseqüência, um problema social de importância extremainente relevante. O presente estudo analisa a situaçáo epidemiológica da hanseniase no Municipio de Campinas. O quadro epidemiológico aponta para o controle dos comunicantes de hanseniase neste municipio que continua pouco eficiente, demonstrando necessidade de estudos mais aprofundados que privilegie estes atores sociais tão importantes na cadeia do processo epidemiológico da hanseniase.

UNITERMOS: Hanseníase, Epidemiologia, Comunicante.

\section{INTRODUÇÃO}

Ao analisar a epidemiologia da Doença de Hansen, sentimos um interesse especial em estudar a situação do comunicante intradomiciliar, visto ser o mesmo um elo importante na cadeia do processo infeccioso e no controle da endemia.

$\mathrm{Na}$ medida em que aprofundamos nossos conhecimentos sobre o paciente e hanseníase, notamos lacunas na assistència, notadamente no controle desta doença e em especial do comunicante.

O comunicante da hanseníase é uma pessoa que habita o mesmo domicílio e até convive diariamente com outras pessoas no trabalho, na escola, no lazer em outras relaçóes sociais. Pode ser considerado uma criança, jovem ou idoso, tendo ou não grau de parentesco com o doente de hanseníase. Pela convivencia próxima na família e no

Professor Assistente do Departamento de Finfermagem da Faculdade de Ciéncias Medicas da Universidade Estadual de (iampinas - UNICAMPSP.

- Professor Doutor do I)epartamento de Enfermagem da Universıdade Federal de Sío Carlos .

UFSCar. 
trabalho, o comunicante fica mais exposto ao risco de contrair a doença.

Dessa forma, esse grupo de pessoas tem uma importância epidemiológica significativa em termos de controle da endemia hansênica e passa a se tornar um grupo de risco vulnerável do ponto de vista da cadeia do processo infeccioso ${ }^{7,18}$.

A abordagem do tema "controle de comunicantes" nos cursos e treinamentos porque passamos, além de manuais e textos que lemos, relativos aos mesmos é feita de maneira superficial e é tratada com o título de "vigilância de contatos"28.

Pelas instruçōes normativas a vigilância de contatos estende-se a todos os individuos que durante o convivio intradomiciliar com o doente, foram expostos ao risco de adoecer. Consiste no exame dermato neurológico dos casos novos de todas as formas clínicas de hanseníase de acordo com o caso índice.

Além disso notamos que nas atividades rotineiras de controle e tratamento do doente hanseniano, não é dada a devida atenção ao comunicante. Na convivência intradomiciliar o comunicante desempenha um papel de suma importância porque está ligado ao doente afetiva, social e econômica, assim como um grau de parentesco muito próximo, além de compartilhar diariamente de seus problemas e necessidades.

Acreditamos que com esta proximidade física, o comunicante tenha um maior acesso ao doente e conseqüentemente mais participaçāo no tratamento e controle desta doença que causa tanto sofrimento as pessoas.

No momento atual, nossa preocupação volta-se para os comunicantes como um dos meios de controlar a doença a nível de população.

\section{A HANSENÍASE}

O controle da endemia hansênica no Brasil é motivo de preocupação de autoridades sanitárias e dos profíssionais da área da saúde que estudam este problema.

A hanseníase é definida como uma doença infecto contagiosa crónica, de longa duração, transmitida de pessoa a pessoa através do contato intimo e prolongado com doentes das formas contagiantes ( Virchoviana ou Dimorfa), sem tratamento. É produzida pelo Mycobacterium Leprae (M. leprae) TALHARI: NEVES ${ }^{28}$. Compromete a pele e preferencialmente, o sistema nervoso periférico. Pode também comprometer os vasos, glàndulas. órgãos internos, aparelho locomotor. boca. laringe, globo ocular, nariz e outros órgãos KAUR et al. ${ }^{13}$ e Brasil ${ }^{3}$. 
As principais fontes de bactérias sāo provavelmente as mucosas das vias aéreas superiores. Também são fontes de bacilos os hansenomas ulcerados, o leite materno, a urina e as fezes.

Nos indivíduos que adoecem, a infecção evolui de maneira diversa, de acordo com as características de resposta imunológica do hospedeiro. Se a resposta imunológica é competente, produz-se uma forma localizada e nāo contagiosa da doença; se essa competência nāo for efetiva, desenvolve-se uma forma generalizada e contagiosa. Entre esses extremos, encontram-se as formas intermediárias, refletindo um largo espectro de variaçōes de resistência (ROTBERG, 1979) ${ }^{24}$.

Não é muito fácil identificar a fonte de infecção ou a localizaçāo inicial do contágio. Isto se constitui no mais sério e importante problema para o controle da epidemia desta doença.

\subsection{Classifícação da Doença}

A classificaçāo atualmente adotada nos serviços públicos de saúde brasileiros (e nesta pesquisa) resultou do VI Congresso Internacional de Leprologia, realizado em Madri, em 1953. Nesse Congresso manteve-se a proposta do Congresso de Havana (1948) de classificar a doença segundo sua tendência de evoluir em direçāo a um dos seus polos, Virchoviano ou Tuberculóide.

Assim, conforme o Ministério da Saúde ${ }^{7}$, qualquer que seja a classificação deve basear-se em quatro critérios, como o clínico, imunológico, bacteriológico e his topatológico. Encontram-se portanto quatro formas básicas de hanseníase. Indeterminada (I), Tuberculóide (T), Virchoviana (V) e Dimorfa (D).

$\mathrm{Na}$ classificaçāo da forma de hanseníase de que o paciente é portador, além da sitomatologia clínica e histopatológica, é de grande utilidade o teste de Mitsuda. "Não é uma prova de diagnóstico, mas pode ser útil na classificaçāo de um paciente, uma vez feito o diagnóstico" (ORGANIZACION PANAMERICANA DE LA SALUD) $)^{20}$.

O resultado do teste de Mitsuda, atualmente, é também utilizado para reagrupar os pacientes para implantação dos novos esquemas terapèticos (poliquimioterapia). Esse reagrupamento resultou em algumas readequaçōes na nomenclatura. Nesse contexto, usam-se os termos multibacilares e paucibacilares. São considerados multibacilares os pacientes portadores da forma virchoviana, dimorfa e indeterminada com Mitsuda negativo. São paucibacilares os pacientes portadores da forma tuberculóide e indeterminada com Mitsuda positivo (BRASIL)? 


\subsection{Caracterização Épidemiológica}

Estima-se que existem atualmente aproximadamente 10 a 12 milhōes de casos de portadores de hanseníase no mundo (OMS) ${ }^{19}$.

Autores que analisam o crescimento da endemia apontam que essa situação pode estar ligada a fatores importantes como o diagnóstico incompleto, despreparo dos profissionais da área da saúde nas açóes assistenciais (tratamento dos doentes, controle e acompanhamento dos comunicantes) e educativas (trabalho de grupos, palestras, visitas domiciliares) visando a promoção e prevençáo dos portadores de hanseníase.

Outras causas apontadas falam em favor dos preconceitos e estigmas dos profissionais da área da saúde como barreira para o desenvolvimento de um programa no controle da hanseníase junto ao doente e seus comunicantes, ou seja seus familiares.

Para estimar a endemia hansênica no mundo, apresentamos os dados da (OMS) ${ }^{19}$.

Para 1988 foram estimados respectivamente 10 a 12 milhōes de casos, sendo que o número total de casos em registro ativo em 1987 foi de aproximadamente 5.100 .000 .

Vale ainda lembrar que mais de um milhäo e 600 mil pessoas, vivem em locais onde a hanseníase constitui um grande problema de saúde, isto é onde a prevalência da doença é maior que um caso em cada 1.000 habitantes, e desse modo, as pessoas correm um sério risco de contrair a doença principalmente nos países em desenvolvimento onde há uma precária cobertura dos serviços de saúde para a hanseníase, acrescido de pessoal despreparado e nāo aderente as dificuldades e necessidades dos pacientes hansenianos e sua família.

$\mathrm{Na}$ América Latina, cerca de 126 milhōes de pessoas ( $31 \%$ da população) vivem em áreas com taxa de prevalência superior a 1 por mil, o que é considerado alto.

A OPAS ${ }^{20}$ considera como área de alta endemicidade aquelas que apresentam coefícientes de prevalência superiores a 1,0 caso por mil habitantes. Estes dados colocam o Brasil como o quarto país do mundo em número de casos, suplantado apenas pela Índia, Birmània e Nigéria, sendo portanto um país com alta endemicidade da doença, e possuindo um coeficiente de prevalência de 2,0 a 4,9 por 1.000 habitantes. Áreas com coeficientes inferiores a 0,2 casos por mil habitantes são considerados de baixa endemicidade. enquanto que coeficientes entre 0,2 e 1,0 por mil habitantes correspondem às áreas de média endemicidade.

No Brasil a hanseniase é encontrada em todo o território nacional, sendo sua distribuição desigual entre as macro regiōes. destacando áreas de baixa. média e alta endemicidade. 
O Brasil detém $85 \%$ dos pacientes de hanseníase das Américas, apresentando em 1989 "a maior taxa de deteç̧ão historicamente observada com 266.578 doentes em registro ativo. A estimativa é de que até 1994, 175.903 casos novos deverão ser detectados ${ }^{4}$.

Analisando a portaria $n^{2} 814$ de 22 de julho de $1993^{8}$ do Ministério da Saúde que dispóe sobre Programa de Controle e Eliminação da Hanseníase detectamos que a mesma enfatiza a importância da vigilância dos contatos como uma forma de interromper a cadeia de transmissão da endemia no país. Observamos que a maioria dos casos quando săo diagnosticados já apresentam a forma clínica da doença numa fase avançada (T.V-D).

Para comprovar esta afirmação apresentamos sumariamente a porcentagem de casos na forma clínica descrita ${ }^{4}, 54,69 \%$ sảo Virchovianos e Dimorfos, 23,55\% Tuberculóides, 20,69\% Indeterminados e $1,07 \%$ nāo estão classificados, significando que os casos iniciais da doença são diagnosticados pelos serviços em baixa porcentagem.

Das 5 macrorregiōes do Brasil, 4 são de alta prevalência: Norte (4,54/1.000); Centro-Oeste (3,41/1.000); Sudeste (1,72/1.000) e Sul $(1,24 / 1.000)$ e o Nordeste com baixa prevalência $(0,86 / 1.000$ habitantes $)^{4}$.

Esses dados apresentados acima corroboram os de LOMBARDI $(1990)^{14}$, que apontam ser a hanseníase encontrada em todo o território brasileiro com distribuiçáo desigual e portanto com áreas de baixa, média e alta endemicidade.

Observando a tendência da endemia hansênica em vários países, através da análise retrospectiva de uma série temporal das taxas de detecção da hanseníase nos países da regiāo ${ }^{21}$, percebemos que em vários deles a endemia parece estar declinando ou permanece estacionária. No entanto, a situação do Brasil parece ser inversa. já que a "linha de tendência dos últimos 13 anos analisados (1970-1983) é ascendente"(OPAS) ${ }^{21}$.

Um outro estudo mais recente mostra a tendência de crescimento da hanseniase no Brasil por macrorregióes e unidades federadas, através do estudo da série histórica de taxas de deteç̧ão de 1973 a 1989. A média de crescimento da endemia neste estudo é de $5,00 \%$ ao ano. Analisando segundo macrorregioos do país, a Nordeste e CentroOeste apresentam as maiores tendèncias de crescimento anual da hanseníase $(11,0$ e $7,00 \%)$.

As regiōes Sudeste e Sul tem ambas média de crescimento anual em torno de $3 \%$.

Acrescenta-se que ao longo das décadas de 70 e 80 , vem-se observando um aumento na detecçáo de casos novos no pais.

Em 1989 foram registrados 27.837 casos novos de hanseniase. maior número historicamente observado. com uma taxa de detecçảo 
de $18,88 / 1.000$ habitantes 4 . Houve um incremento de $4,74 \%$ com relação à deteç̧ão de 1988 (26.578), confirmando a tendência de crescimento prevista.

Dos 27.837 casos novos detectados em 1989, 9,97\% säo menores de 15 anos, proporção considerada alta segundo parâmetros do BRASIL $4,87,16 \%$ tem idade maior que 15 anos e 2,87\% idade ignorada.

$\mathrm{E}$ importante lembrar que as regiōes Norte, Nordeste e CentroOeste que tem respectivamente a maior taxa de prevalência e maiores tendências de crescimento săo as que tem maiores proporçóes de doentes com idade menor que 15 anos.

Ao analisar os dados do Estado de Sāo Paulo, verificamos que o programa de controle da hanseníase faz parte dos Programas Especificos da Secretaria de Estado da Saúde, constituindo-se em um conjun to de açóes de saúde programadas e normatizadas BRASIL ${ }^{1}$. Dessa forma há uma readequaçāo das diretrizes e estratégias para as açōes de controle da hanseníase de acordo com a proposta de saúde atual BRASIL ${ }^{2}$.

Em relaçāo a tendência da endemia vemos no gráfíco 1 que, na região Sudeste, este Estado apresenta a menor taxa de incremento a nual embora seja considerado área de alta prevalência.

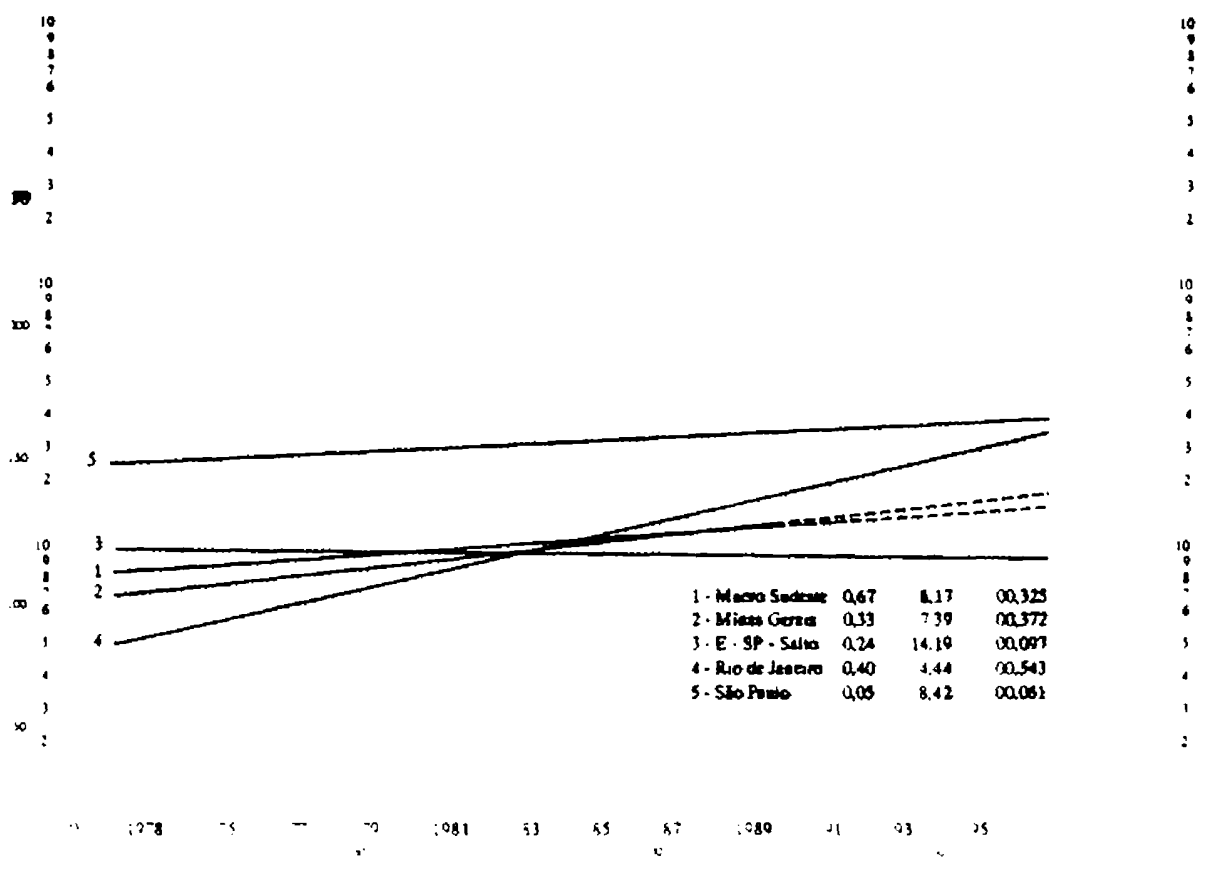


Frente a essa situação apontada vale a pena analisar algumas situaçōes que tem dificultado a operacionalizaçāo do controle da endemia hansênica a nível local. Uma das questões muito discutidas pelo Centro de Vigilância Epidemiológica é a qualidade da coleta de dados. Este mesmo centro relata um alto índice de näo informados e erros de preenchimento de dados. O que confirma esta situação é a grande taxa de abandono e altos percentuais de casos sem avaliação de incapacidades.

No Encontro Estadual de Avaliação do Programa de Controle da Hanseniase $1992{ }^{6}$ ocorrido em maio de 1993 foram levantados os pontos principais que dificultam o sistema de controle da endemia. Dentre eles podemos citar:

a) ausência de uma diretriz técnica do controle das endemias em conjunto com os municípios.

b) desconhecimento da magnitude e gravidade do problema da hanseniase por parte de algumas autoridades locais e regionais.

c) falta de preparo gerencial nos diferentes niveis do sistema.

d) hipertrofia das atividades do pronto atendimento em detrimento das atividades programáticas.

e) nāo realizaçāo da atividade de visita domiciliar ou da convocaçāo de faltosos por deslocamento de recursos humanos para outras atividades.

f) formas de financiamento do sistema de saúde como entrave para as atividades como vigilância e açóes programáticas.

Ainda foram levantados outros pontos como: alta rotatividade de pessoal devido falta de política salarial condizente, falta de gerenciamento, etc.

Frente ao exposto e considerando a necessidade de se ter o conhecimento real e sistematizado dos dados da Regiảo de Campinas. especialmente das atividades de saúde, onde se desenvolve o ensino do Curso de Graduação em Enfermagem da Universidade Estadual de Campinas, procuramos desenvolver este estudo, tendo como objetivo a apresentaçāo dos dados epidemiológicos, assim como a análise dos fatores que contribuem para essa realidade e ainda realizar uma análise crítica sobre o controle dos comunicantes no Município de Campinas.

Os dados do presente estudo foram obtidos junto ao Grupo Municipal de Vigilância Epidemiológica de Campinas, documentos técnicos existentes nos Serviços de Saúde e ainda dos prontuários dos pacientes atendidos nas Unidades de Saúde.

Neste momento passamos a caracterizar a realidade existente no local estudado. 


\section{A SITUAÇÃo EPIDEMIOLÓGICA DA HANSENÍASE EM CAMPI- NAS}

Considerando que o Estado de São Paulo, está dividido em cinco regiōes de Saúde, a cidade de Campinas, local desse estudo, encontrase localizada na Coordenaçáo de Regiōes de Saúde 4 (regiäo do Vale do Paraíba - CRS-4).

O modelo de Saúde vigente (SUS) prevê a unificação de todos os serviços estaduais e municipais de saúde e dentro desta reforma administrativa estadual, foram estabelecidos convênios de municipalização para a integração administrativa de todos os municípios.

No momento atual Campinas possui 40 unidades básicas de saúde, entretanto estão estruturadas para o atendimento de hanseníase somente cinco unidades. Destas cinco, o Centro de Saúde I de Campinas (atual Policlínica) atende 93,6\% dos pacientes doentes, conforme dados do Centro de Vigilância Epidemiológica.

Em dezembro de 1989, o Centro de Vigilância Epidemiológica da Secretaria do Estado da Saúde apurou a seguinte distribuição dos casos registrados de hanseníase segundo a forma clínica, Tabela 1.

\section{TABELA 1 - DISTRIBUIÇĀO DOS CASOS REGISTRADOS DE HANSENÍASE SEGUNDO A FORMA CLÍNICA, CAMPINAS - Dezembro/1989}

\begin{tabular}{lcr}
\hline Forma Clínica & \multicolumn{3}{c}{ Casos Registrados } \\
\cline { 2 - 4 } & $\mathrm{N}^{2}$ & $\%$ \\
\hline Virchoviana & 685 & 63,7 \\
Dimorfa & 51 & 4,7 \\
Indeterminada & 178 & 16,5 \\
Tuberculóide & 162 & 15,1 \\
\hline Total & 1.076 & 100,0 \\
\hline
\end{tabular}

FONTE: CVE-SP (Centro de Vigilància Epidemiológica).

A figura 2 mostra que o coeficiente de detecção no município de Campinas, no período de 1982 a 1990 , manteve-se em níveis de 8,65 por 100.000 habitantes, em 1989 chegando a 9,82 no ano de 1983 . Sendo que nos anos de 1984 e 1987 verificou-se declínio acentuado de 7,36 e 5,94 por 100.000 habitantes respectivamente, o que se deve especialmente a falta de recursos humanos na rede, refletindo a baixa detecção dos casos. 


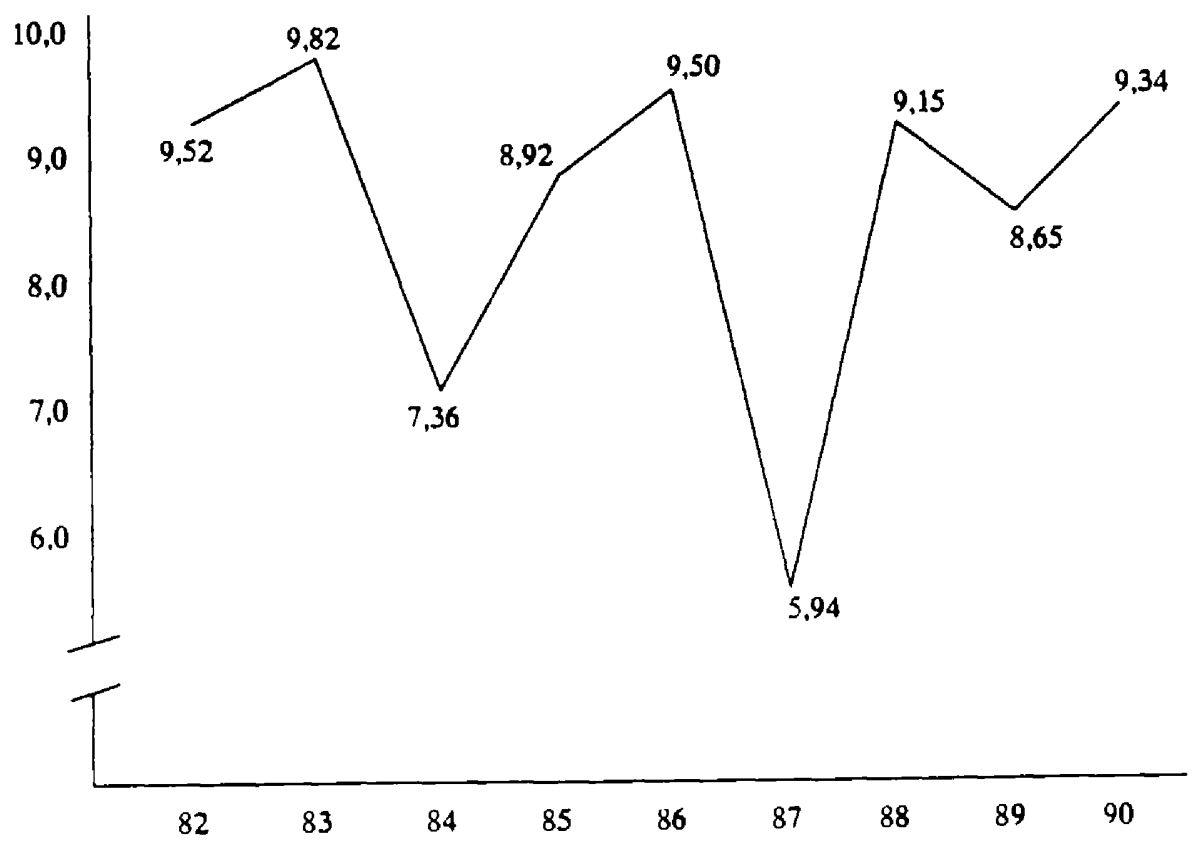

GRÁFICO 2 - Incidência da hanseniase no município de Campinas no período de 1982-1990

Com uma populaçāo de 912.844 habitantes e um total de 1.076 pacientes de hanseniase, em registro ativo, Campinas tem uma prevalência de 1,17 casos por mil habitantes. Estes dados mostram que a cidade possui um coeficiente de prevalência considerado alto pela OMS. Assim, observa-se que além desta doença não estar sendo controlada na regiāo, evidencia-se também pelos dados da tabela 1 que o diagnóstico dos casos é freqüentemente tardio. Ou seja, são detectados nas fases avançadas da doença ( $83,5 \%$ dos casos), demonstrando uma deficiência do controle desta doença nas Unidades de Saúde.

A Tabela 2 mostra a distribuição dos casos novos, segundo a unidade de seguimento. Esses dados tem como fonte o GMVE - Grupo Municipal de Vigilância Epidemiológica. CAMPINAS ${ }^{9}$

Dessa forma a Policlínica de Campinas detém 91,0\% dos casos novos de hanseníase com aproximadamente 80 casos novos. 
TABELA 2 - DISTRIBUIÇĀO DOS CASOS NOVOS, SEGUNDO A UNIDADE DE SEGUIMENTO - Campinas, 1980

\begin{tabular}{lcr}
\hline Unidade de Seguimento & \multicolumn{2}{c}{ Casos Novos } \\
\cline { 2 - 3 } & $\mathrm{N}^{2}$ & $\%$ \\
\hline Policlínica & 80 & 91,0 \\
Barāo Geraldo & 4 & 4,5 \\
HC-UNICAMP & 4 & 4,5 \\
Santa Odila & - & - \\
Taquaral & - & - \\
\hline Total & 88 & 100,0 \\
\hline
\end{tabular}

FONTE: GMVE (Grupo Municipal de vigilância Epidemiológica).

A distribuiçāo dos casos novos de hanseníase por forma clínica e faixa etária sāo encontrados na Tabela 3. Na faixa etária de 15 anos e mais estāo concentrados $97,7 \%$ das formas clínicas com predominância da Virchoviana ( 36 casos) e Tuberculóide ( 24 casos). A proporção de menores de 15 anos entre os casos novos é de 2:88 casos ou seja, $2,3 \%$. Para a OMS é considerado um parâmetro baixo quando encontramos dados menores do que $4 \%$.

TABELA 3 - DISTRIBUIÇĀO DOS CASOS NOVOS DE HANSENÍASE SEGUNDO A FORMA CLÍNICA E FAIXA ETÁRIA - Campinas, 1990

\begin{tabular}{lrrrr}
\hline Forma Clínica & \multicolumn{3}{c}{ Faixa Etária } & Total \\
\cline { 2 - 5 } & 15 & 215 & $\mathrm{~N}$ & $\%$ \\
\hline Dimorfa & 0 & 7 & 7 & 8,0 \\
Indeterminada & 1 & 19 & 20 & 22,7 \\
Tuberculóide & 1 & 24 & 25 & 28,4 \\
Virchoviana & 0 & 36 & 36 & 40,9 \\
\hline Total & 2 & 86 & 88 & 100,0 \\
& $(2,3 \%)$ & $(97,7 \%)$ & & \\
\hline
\end{tabular}

FONTE: GMVE (Grupo Municipal de Vigilância Epidemiológica.

Proporção de Menores de 15 anos entre os casos: $(2 / 88)=2,3 \%$

Parâmetros: Alto: $\geq 8 \%$

Médio: $4 \mid-8 \%$

Baixo: $4 \%$ 
Esses dados apresentados caracterizam a questão epidemiológica e social da hanseníase apontando a necessidade de um equacionamento maior das relaçóes existentes junto ao próprio serviço de saúde e aos doentes ali atendidos.

\subsection{A Situaçāo dos Comunicantes}

O Estado de São Paulo, muito embora apresente resultados que evidenciam a proximidade do controle efetivo da doença, a situação é ainda preocupante tendo em vista o elevado número absoluto de casos; reforçando, a importância do desenvolvimento de esforços, objetivando o controle da endemia.

Um dos pontos essenciais que consideramos de fundamental importância no controle epidemiológico da doença e sem dúvida contribuem para o entendimento das condiçōes reais de vida do grupo em questão, é o estudo sobre os comunicantes. Vale ressaltar que as características apontadas tanto pelos doentes, quanto pelos comunicantes nos permite identificar as idéias, imagens e concepçōes de visão de mundo que esses atores sociais possuem sobre a realidade ${ }^{17,29}$.

Os estudos realizados sobre os comunicantes são em número reduzido e sua abordagem privilegia fundamentalmente a análise epidemiológica do problema ${ }^{11,16,23,25,27}$, sem destacar a inserção desse comunicante (assim como do doente) dentro da estrutura social e a concepção que o mesmo tem sobre a questão da saúde/doença ${ }^{13.18,30}$.

O conhecimento das condiçōes de vida, suas crenças e representaçōes de mundo aí envolvidas, presentes nas relaçōes, nas falas, nas redes simbólicas e afetivas vai pouco a pouco compondo o modo de vida do indivíduo, no nosso caso o comunicante.

Para discutir sobre a saúde do homem há que considerar uma imensa gama de situaçōes como condiçóes de trabalho, moradia, cuidados consigo próprio e com sua família, relaçōes a fetivas e sociais que por sua vez determinam a concepção de doença, sua historicidade e os meios de combatê-la.

Nossa preocupação dirige-se ao comunicante de hanseniase, pois acreditamos que esta área carece de estudos mais aprofundados que privilegie estes atores sociais tão importantes na cadeia do processo epidemiológico da hanseníase.

Apresentamos a seguir a distribuiçáo dos comunicantes e casos de hanseníase, segundo tipo de tratamento e avaliação dos comunicantes, na Policlínica de Campinas (Tabela 5) e podemos verificar uma situaçáo precária dos mesmos, com apenas $23,8 \%$ do total de avaliados, o que não difere de dados obtidos através de observaçóes empíricas realizadas em outras unidades de saúde. 
Dos pacientes sob esquema de tratamento tradicional (DNDS) apenas $19,8 \%$ dos seus comunicantes foram avaliados. Por outro lado daqueles pacientes em tratamento poliquimioterápico, $45,5 \%$ de seus comunicantes passaram pela avaliação da Unidade de Saúde. Assim sendo, estes dados refletem uma deficiência desta atividade neste serviço.

TABELA 5 - DISTRIBUIÇĀO DOS COMUNICANTES DE CASOS DE HANSENIASE EM SEGUIMENTO NA POLICLÍNICA DE CAMPINAS, ANO DE 1989, SEGUNDO TIPO DE TRATAMENTO E AVALIAÇĀO DOS COMUNICANTES

\begin{tabular}{|c|c|c|c|c|c|c|}
\hline \multirow[t]{3}{*}{ Tipo de Tratamento } & \multicolumn{6}{|c|}{ Avaliaçäo de Comunicantes } \\
\hline & \multicolumn{2}{|r|}{ Sim } & \multicolumn{2}{|r|}{ Nảo } & \multicolumn{2}{|r|}{ Total } \\
\hline & $\mathrm{N}$ & $\%$ & $\mathrm{~N}$ & $\%$ & $\mathrm{~N}$ & $\%$ \\
\hline $\begin{array}{l}\text { Tradicional } \\
\text { (DMDS) }\end{array}$ & 432 & 19,8 & 1.750 & 80,2 & 2.182 & 84,1 \\
\hline $\begin{array}{l}\text { Poliquimioterapia } \\
\text { (PQ1) }\end{array}$ & 187 & 45,5 & 224 & 54,5 & 411 & 15,9 \\
\hline Total & 619 & 23,8 & 1.974 & 76,2 & 2.593 & 100,0 \\
\hline
\end{tabular}

FONTE: GMVE (Grupo Municipal de Vigilância Epidemiológica) Policlínica.

Como uma forma de controle da endemia a prevenção da doença a portaria $\mathrm{n}^{8} 814$ de 22 de julho de 1993 do Ministério da Saúde ${ }^{5}$ dispóe sobre a vacinaçáo dos contatos intradomiciliares de hanseníase com BCG-ID (intradérmico). Os contratos (comunicantes) devem ser vacinados com duas doses, com intervalo de 6 meses entre as duas doses.

Acredita-se que a vacinação protege contra ao aparecimento de formas multibacilares, a partir da segunda dose. A decisão de se vacinar contatos de paucibacilares deve-se ao fato de que estes contatos podem estar expostos a mesma fonte de infecçāo.

O Plano de Metas da avaliação das atividades desenvolvidas no Estado de São Paulo, nos últimos anos, tem demonstrado que o controle dos doentes continua pouco eficiente e conseqüentemente, a endemia não vem sendo controlada.

Esta é uma realidade corroborada por GONÇALVES ${ }^{12}$, onde afirma que é muito variável o percentual que se observa para o controle de comunicantes e que, no país como um todo, aproximadamente só 1 em 3 está sob vigilância epidemiológica. 
O aumento da incidência da hanseníase em São Paulo e mais particularmente em Campinas e a tendência ascendente da mesma, nos obriga a repensar a situação dos comunicantes de hanseníase antes que se tornem doentes.

PEDRAZZANI ${ }^{22}$ analisando a situação do controle dos comunicantes vem mostrar que há carência de estudos que relatam a realidade das unidades sanitárias do país em relação ao controle dos mesmos.

Seus achados mostram a necessidade que esse controle seja feito nāo só com o doente, mas também com os comunicantes. Aponta ainda para a dificuldade de trabalhos nesta área devido os preconceitos e tabus que envolvem a doença hanseníase.

Sugere que se adote algumas medidas relacionadas a educação sanitária da população em geral e em especial a pacientes, comunicantes e aos próprios profissionais que atuam nesta área.

É importante destacar que todo portador de hanseníase foi primeiramente um comunicante e que aproximadamente $70 \%$ deles não foram diagnosticados na forma inicial da doença, acarretando sérios prejuízos físicos, psíquicos, sociais e econòmicos.

Visto ser a hanseníase uma doença curável em todas as suas formas e a vigilância de contatos uma atividade importante preconizada pelo Ministério da Saúde em suas instruçōes normativas, faz-se necessário um trabalho mais eficaz junto aos comunicantes como forma de contribuir para o diagnóstico precoce e o controle da endemia.

\section{CONSIDERAÇŌES FINAIS}

Sabemos que a hanseníase está vinculada à situação de pobreza, baixa renda e saneamento básico insuficiente, condições precárias de higiene e alimentação, atingindo uma parcela da população em plena fase da sua vida produtiva.

Os dados obtidos nos mostram que a distribuiçāo da doença em Campinas nāo difere da realidade do Estado de São Paulo, ressaltando a baixa deteç̧ão de casos em menores de 15 anos $(2,3 \%)$ e a grande concentraçāo $(91 \%)$ de atendimento de doentes existentes em uma unidade de saúde, o que reforça a prática de não universalizar o atendimento nos serviços existentes.

Em relação aos comunicantes este estudo reforça a necessidade de se desenvolver pesquisas junto aos mesmos como forma de buscar o atendimento mais profundo do papel desse comunicante na cadeia epidemiológica. quais suas percepçōes em relaçāo à doença e ao doen- 
te, visando contribuir para o diagnóstico precoce e o controle da endemia hansênica.

CARRASCO, M. A. P.; PEDRAZZANI, E. S. The epidemiological status of Leprosy pacients and their communiccants in Campinas. Rev. Esc. Enf. USP., v. 27, n. 2, p. 214-28, aug. 1993.

Leprosy is a highly prevalent, endemic disease in this country. Due to its long evolution, it gives rise to an extremely important social issue. This paper analyses the epidemiologic status of Leprosy in the municipality of Campinas. The epidemiologic framework indicates that control of leprosy communicants in Campinas remains inefficient, showing the need for further studies upon these social actors, important links in the epidemiologic sequence of this disease.

UNITERMS: Leprosy, Epidemiology, communicants.

\section{REFERÊNCIAS BIBLIOGRÁFICAS}

1. BRASIL. Leis, etc. Resoluçāo SS-122. Diário Oficial da Uniāo, Brasilia, 18 de maio de 1990. Seçáo 1, p.11.

2.

Resolução SS-129, de maio de 1990. Diário Oficial do Eatado, Sāo Paulo, 18 de maio de 1990, Seçáo 1,p.11

3. Brasil. Ministério da Saúde. Guia para controle da hanseniase. Brasilia, 1984.

4.

Henseniase: uma endemia ascendente no Brasil: rela. tório de atividades. Brasilia, 1990

5.

Normas e procedimentos para aplicaçào da vacina BCG em contatos intradomiciliares de hanseníase, Brasûia, 1993.

6.

Programa de controle da hanseniase. São Paulo. Centro de Vigilância Epidemiológica Professor Alexandre Vranjac. 1992

7.

Controle de hanseníase: uma proposta de integração ensino-serviço. Rio de Janeiro OMS/NUTES, 1989. p. 15-94

8. Portaria n. 814 de 22 julho de 1993, p.51-5.

9. CAMPINAS (Cidade).Prefeitura Municipal. Grupo Municipal de Vigilancia Epidemiologica. Campinas, 1989./mimeografado/

10. FASSIN, D. Influence of social perceptions of leprosy and leprosy patients of public health programs. IntJ.Lepr.Other Mycobact Dis, v.58, n.1, p. 11-4, 1990.

11. GEORGE, K. et al. The Role of intrahousehold contact in the transmission of leprosy. Lepr.Rev., v.61, n.1, p. 60-3, 1990.

12. GONÇALVES, A.G. Epidemiologia e controle da hanseniase no Brasii, s.1., 1989./mimeografado/

13. KAUR, S. et al. Respiratory system involvement in leprosy. Int.J.Lepr.Other Mycobact Dis., v.47, p. 18-32, 1979.

14. LOMBARDI, $C$. et al. História natural da hanseniase. In:LOMBARDI. C. (Coord.) Hanseniase: epidemiologia e controle. São Paulo. Imprensa Oficial do Estado, 1990.

15. LORD, R. et al. Skin test studies on close contacts of leprosy patients in Indian. Int.J.Lepr.Other Mycobact Dis, v.57, n.4, p.801-9, 1989. 
16. MA HD et al. Studies on social medicine and leprosy in last China. Proc.Chindend.Med.Sci.Peking Union Med.Coll., v.4, n.2, p. 61-4, 1989.

17. MINAYO, M.C. de. O Desafio do conhecimento: metodologia de pesquisa social qualitativa em saúde. Rio de Janeiro. 1989. Tese (Doutorado)-Escola Nacional de Saúde Pública.

18. NOUSSITOU, F.M. et al. A Lepra na Criança. Itália, Associazione Italians "Amici di Reoul Follereau", 1981.

19. ORGANIZACION MUNDIAL DE LA SALUD. Comitè de Expertos de la OMS en Lepra: serto informe. Ginebra, 1988. (Série de Informes Técnicos, 768).

20. ORGANIZACION PANAMERICANA DE LA SALUD. Manual para o controle da lepra. 2.ed. Washington, 1989.

21. ORGANIZACION PANAMERICANA DE LA SALUD. Situacions de log Programas de controles de la lepra en las Américas. Washington, 1988. p. 8

22. PEDRAZZANI, E.S. et al. Controle dos comunicanteo: sua interferência na situaçảo epidemiológica da hanseniase. Hansenol.Int., v.11, n.1/2, p.44.54, 1986.

23. RAMESH, V. Eet al. How to detect leprosy in some patients with only localized sensory lose/letter/. Lepr.Rev., v.61, n.1, p. 79-80, 1980.

24. ROTEBERG, A. Noçōes de hansenologia. São Paulo, Fundaçāo Paulista contra a hanseniase, 1979.

25. SAMPATAVANICH, $\mathrm{S}$. et al. Immunoepidemiological studieo on subclinical infection a mong leprosy contacts in Thailand. Lepro.Rev., v.61, n.2, p. 35.40, 1981.

26. SÁO PAULO (Estado). Secretaria de Estado da Saúde. Coordenadoria de Saúde da Comunidade. Sub-programa de controle da hanseniase. São Paulo, 1977./mimeografadol

27. SUNDARRAO, P.S. et al. Impact of MDT on incidence rates of leprosy among household contact: Baseline data Parte 1. Int.J.Lepr.Other Mycobact Dis., v.57, n.3, p. $647.51,1989$.

28. TALHARI, S; NEVES, R.G. Hangeniase. 2.ed., Instituto Superior de Estudos da Amazônia, 1989.

29. THIOLLENT, M. Crítica metodológica, investigaçảo social e enquete operária. j.ed. Sāo Paulo. Polis, 1987.

30. VALENCIA, L.B. Social science research on social dimensions of leprosy: where are we going from here? Int.Lepr.Other Mycobact Res., v.57, n.4, p.847.63, 1989. 